\title{
CREASED-PLASTIC ROCK PERMEAMETER FOR HYDROGEOLOGY STUDENTS
}

\author{
Paul F. Hudak Department of Geography and Environmental Science Program, University of North Texas, \\ Denton, TX 76203-5279, hudak@unt.edu
}

\section{ABSTRACT}

Inexpensive rock permeameters made from overhead transparency sheets and flexible tubing were built in an introductory hydrogeology course. They operate in a falling-head mode - water drains down a tube connected to the base of a plastic rock chamber. A hydraulic conductivity value of $3.2 \times 10^{-5} \mathrm{~cm} / \mathrm{s}$ was calculated for a four-sided sandstone specimen from the Woodbine Formation. Similar values were obtained in a second test on the same specimen, a third test on a six-sided specimen, and a fourth test using a conventional falling head permeameter. Students preferred building creased-plastic permeameters and calculating hydraulic conductivity values rather than being given a hydraulic conductivity value in a problem statement. Creased-plastic permeameters cannot withstand air vacuums (as sometimes used while saturating a sample with water) and may leak if poorly constructed or used with nearly impervious rocks. For these reasons, creased-plastic permeameters are not suited to research. However, they provide an inexpensive way for students to estimate the hydraulic conductivity of local rock aquifers.

\section{INTRODUCTION}

Recently, there has been much emphasis on computer-based instruction in geoscience courses (Schlische, 1998; Hall-Wallace, 1999). The quantitative nature of hydrogeology is well suited to computers, which focus attention on basic principles and develop problem-solving skills (Reichard, 1999). In the classroom, computers have been used to process aquifer data, model groundwater flow, and visualize contaminant transport (Hudak, 1998; Lee, 1998; Renshaw et al., 1998).

Groundwater models require input values for hydraulic conductivity. Often these values are given in the problem statement, or students estimate them from relevant literature. Previous authors have shown that hands-on lab experiments are an effective way to study groundwater flow (Gates et al., 1996; Lee, 1998). As such, quantitative exercises would likely be more informative if students directly calculated hydraulic conductivity values. The objective of this study was to design a simple and inexpensive rock permeameter that students could build to measure hydraulic conductivity in the classroom.

\section{BACKGROUND}

The hydraulic conductivity of an aquifer exerts a strong influence on groundwater flow. In turn, flow rates affect groundwater resource development, pollutant transport, and aquifer remediation. Aquifer tests and laboratory permeameters often measure hydraulic conductivity. Permeameters have been deployed in the absence of wells, or where local-scale estimates of hydraulic conductivity were required (ASTM, 1997).

Cylindrical permeameters having rigid or flexible walls (ASTM Method 5084) can effectively measure unconsolidated samples, but often encounter problems with lithified rock. Rocks that do not fit snugly against the walls of a permeameter allow water to bypass the sample, leading to artificially high hydraulic conductivity estimates. Short-circuiting is more problematic in rigid permeameters, but also affects flexible wall permeameters used with non-cylindrical rock samples.

Gas permeameters (ASTM Method 4525) often measure the hydraulic conductivity of rock cores. These permeameters include laboratory devices that hold cores in sleeves and portable probe devices that can be used in the field. Probe devices perform localized, rapid, non-destructive gas permeability measurements on a variety of core surfaces. However, both laboratory and probe gas permeameters are rather expensive and not readily available to many students and practitioners. Moreover, the laboratory devices require considerable installation and training effort. Gas permeability measurements can be made by technicians, but costs start around $\$ 120$ per sample, and students do not participate in the measurement.

Due to the limitations outlined above, conventional permeameters are not well suited for use by undergraduate hydrogeology students studying lithified rocks. This paper describes an alternative approach for measuring the permeability of rock aquifers in which students build a permeameter with easily obtained and inexpensive supplies.

\section{METHODS}

Permeameters were constructed with plastic sheets - the kind used for overhead transparencies during lectures. A typical "creased-plastic permeameter" requires only one transparency sheet (Figures 1 and 2). Other supplies include a 0.5 -in $(1.3-\mathrm{cm})$ electrical ADT adapter for PVC, a 3 -ft $(0.9-\mathrm{m})$ length of 0.5 -in $(1.3-\mathrm{cm})$ inner-diameter, clear, flexible tubing, and silicone. Steps for constructing a creased-plastic permeameter are detailed below.

1. Obtain a fairly flat rock sample, approximately 0.5 in $(1.3 \mathrm{~cm})$ to 1.5 in $(3.8 \mathrm{~cm})$ thick, with an area (over the broadest face of the rock) of approximately $1.0 \mathrm{in}^{2}$ $\left(6.5 \mathrm{~cm}^{2}\right)$ to $6.0 \mathrm{in}^{2}\left(38.7 \mathrm{~cm}^{2}\right)$. The rock may be chiseled from outcrop or collected from float. Cut the 


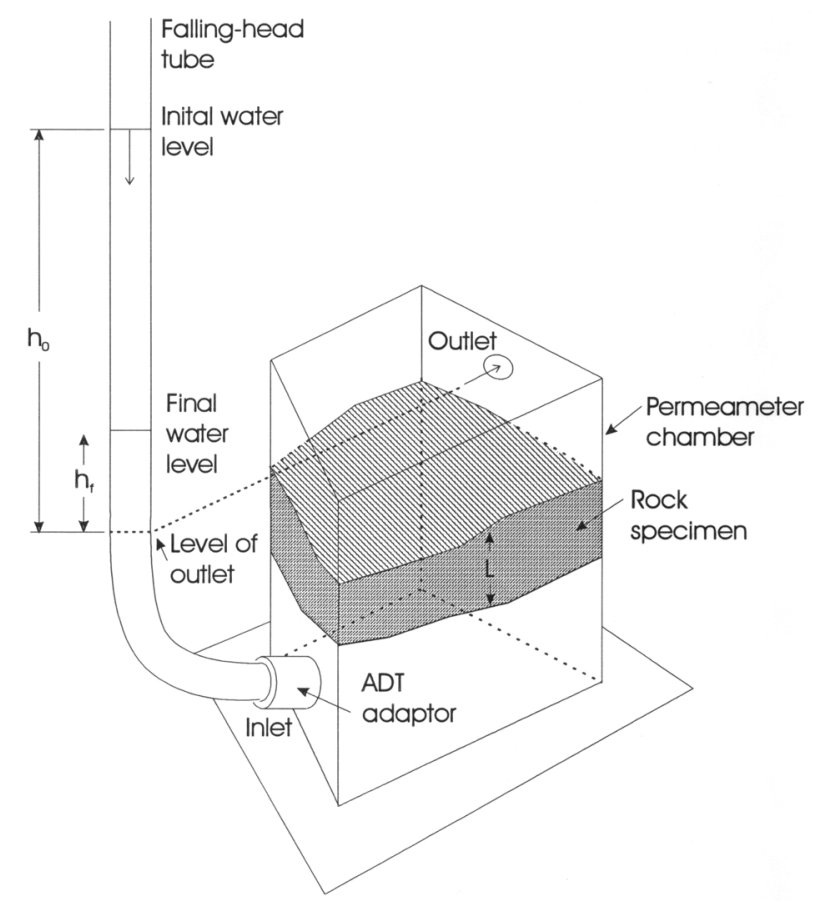

Figure 1. Diagram of creased-plastic permeameter (see text for discussion).

edges of the rock into flat faces to form a polygon with three or more sides. Use a rock/masonry blade with a hacksaw, circular saw, or rock saw to form the polygon.

2. Wrap a transparency sheet around the perimeter of the rock, pushing it gently at the corners to indent the plastic.

3. Remove the plastic sheet, and crease it at the indentations. Mark the transparency overlap area, and cut it to a width of about 0.5 in $(1.3 \mathrm{~cm})$. Trim the transparency to a length that is about 3.0 in $(7.6 \mathrm{~cm})$ greater than the thickness of the rock sample.

4. Put a 0.2-in $(0.5-\mathrm{cm})$ bead of silicone on all sides of the rock (except for the two broader faces through which water will flow). Also put a bead of silicone on the transparency overlap area.

5. Position the rock in the middle of the transparency sheet, and wrap the sheet back around the rock, pushing it against the silicone. Do not press the silicone bead to a thickness less than 0.1 in $(0.3 \mathrm{~cm})$. Wrap masking tape around the permeameter where it contacts the rock to temporarily hold it in place. Press together the overlap area above and below the rock. Rest the permeameter on its side, let it dry, and remove the tape. Examine the silicone bead between the rock and plastic. If the bead is not continuous, remove the plastic, and repeat this step using a new sheet.

6. Cut 0.3 in $(0.8 \mathrm{~cm})$ along each crease at the base of the permeameter. Fold the plastic inward to create tabs
Polygonal rock specimen

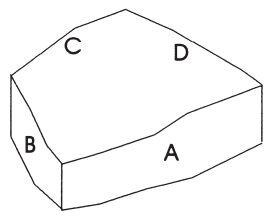

Plan view of plastic sheet

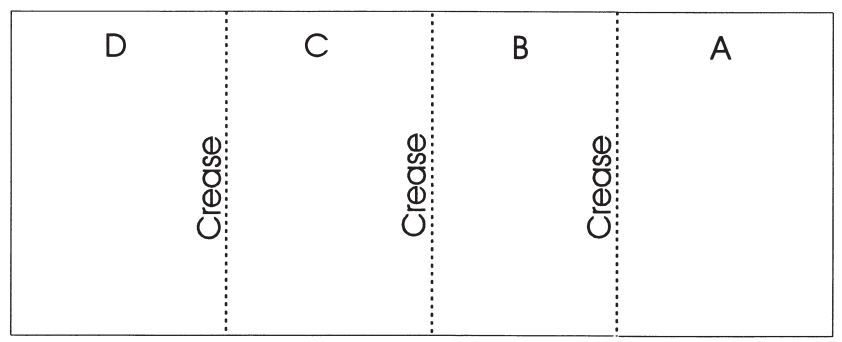

Figure 2. View of hypothetical rock specimen (top) and plastic sheet showing creases.

oriented at $90^{\circ}$ to the walls of the permeameter. The tabs will form the base of the permeameter.

7. Using a knife or hole punch cut a 0.6-in $(1.5-\mathrm{cm})$ hole into one wall of the permeameter, about midway between the rock and tabs. Silicone the electrical adapter and, starting from inside the permeameter, press it into the hole.

8. Cut a 0.3-in $(0.8-\mathrm{cm})$ outlet hole, located about midway between the rock and top of the permeameter.

9. Lay a piece of plastic (transparency sheet), approximately 1.0 in $(2.5 \mathrm{~cm})$ wider (in all directions) than the base of the permeameter, on a table. With tabs down, position the permeameter in the middle of the plastic sheet. Mark the sheet where it intersects the permeameter, remove the permeameter, and spread a bead of silicone over the marked area. Place the permeameter on the bead, pushing the tabs into the silicone to create a seal. Spread a bead of silicone around the permeameter where it contacts the base sheet. Allow the entire assembly to dry for 24 hours.

10. Insert one end of the tube into the adapter. If the tube does not fit snug, use silicone to create a tight seal. Place the permeameter on a table and against a wall. Attach a meter stick vertically to the wall. Tape the tube to the meter stick in 3 to 4 places, including the bottom and top of the tube. Let the permeameter dry thoroughly.

The completed device functions as a falling-head permeameter. Using a beaker, fill the tube slowly, allowing water to drain upward through the rock and outlet. 


\begin{tabular}{|l|c|l|l|l|}
\hline & $\begin{array}{l}\text { Test 1 } \\
\text { (4-sided; creased- } \\
\text { plastic) }\end{array}$ & $\begin{array}{l}\text { Test 2 } \\
\text { 4-sided; creased- } \\
\text { plastic) }\end{array}$ & $\begin{array}{l}\text { Test 3 } \\
\text { (6-sided; creased- } \\
\text { plastic) }\end{array}$ & $\begin{array}{l}\text { Test 4 } \\
\text { (rounded; K-605) }\end{array}$ \\
\hline $\begin{array}{l}\text { Initial water elevation above } \\
\text { outlet (cm) }\end{array}$ & 31.0 & 35.1 & 34.3 & 58.0 \\
\hline $\begin{array}{l}\text { Final water elevation above outlet } \\
(\mathrm{cm})\end{array}$ & 6.2 & 7.6 & 9.0 & 1.1 \\
\hline Test duration (s) & 4,966 & 4,727 & 5,473 & 7,545 \\
\hline Length of sample (cm) & 2.0 & 2.0 & 1.0 & 1.2 \\
\hline Area of sample $\left(\mathrm{cm}^{2}\right)$ & 26.0 & 26.0 & 7.9 & 29.6 \\
\hline Area of tube $\left(\mathrm{cm}^{2}\right)$ & 1.3 & 1.3 & 1.3 & 1.7 \\
\hline $\begin{array}{l}\text { Hydraulic conductivity estimate } \\
(\mathrm{cm} / \mathrm{s})\end{array}$ & $3.2 \times 10^{-5}$ & $3.2 \times 10^{-5}$ & $4.0 \times 10^{-5}$ & $3.6 \times 10^{-5}$ \\
\hline
\end{tabular}

Table 1. Experimental Results

Gently tap the tube to float any bubbles that may have formed while filling the tube. If there are any leaks, dry out the permeameter, and patch them with silicone.

Maintain the water level approximately $50 \mathrm{~cm}$ above the outlet when filling the tube. When the rock is saturated and water is dripping through the outlet, stop filling the tube, record the water level in the tube, and start a timer. Stop the test when the water level has fallen to a few $\mathrm{cm}$ above the outlet, and record the final level.

Apply the falling-head permeameter equation (Todd, 1959) to the data,

$$
K=\frac{A_{t} L}{A_{s} t} \ln \frac{h_{0}}{h_{f}},
$$

where $\mathrm{K}$ is the hydraulic conductivity of the rock sample, $A_{t}$ is the cross-sectional area of the tube, $A_{s}$ is the cross-sectional area (oriented perpendicular to the length of the permeameter) of the rock sample, $\mathrm{L}$ is the average thickness of the rock sample, $t$ is the time duration of the test, $h_{0}$ is the initial water level in the tube (above the outlet), and $h_{f}$ is the final water level in the tube. Refill the tube, and repeat the experiment as desired.

\section{APPLICATION}

A creased-plastic permeameter was used to measure the hydraulic conductivity of friable, medium grained sandstone. The sandstone specimen was poorly cemented with iron oxide and silica. It came from the Upper Cretaceous, Woodbine Formation, a minor aquifer in north central Texas.
A four-sided polygonal sample was cut from the sandstone specimen using a trim saw. The completed permeameter resembles the schematic in Figure 1. Two tests were run on the four-sided sample. A third creased-plastic permeameter test was run on a six-sided sample, and a fourth test was run with a SOILTEST K-605 falling head permeameter on another sample. All of the samples came from the same sandstone specimen. These four tests were run to check the precision of the creased-plastic permeameter, whether the number of sides affected the result, and how the creased-plastic test compared to a conventional test. Test parameters and results are listed in Table 1.

Creased-plastic permeameters were also built and used by students in a hydrogeology laboratory. They followed the 10 steps outlined above and viewed a completed permeameter while building their permeameters.

\section{DISCUSSION}

Permeameter Test Results - The creased-plastic permeameter duplicated hydraulic conductivity estimates in successive tests on the four-sided sample (Table 1). Similar results were obtained for a smaller six-sided sample in a creased-plastic permeameter, and for a larger, rounded sample in the K-605 permeameter. Using different samples and measurement error caused slight differences between the four test results.

If properly constructed, the number of sides on a sample should not affect the hydraulic conductivity estimate from a creased-plastic permeameter. Rock samples used with creased-plastic permeameters require three or more 
flat sides. In some cases it may be easier to trim an irregularly shaped sample into several flat sides.

Feedback from Students - Creased-plastic permeameters were useful for teaching hydraulic conductivity. Students commented that using creased-plastic permeameters was more meaningful than being given a hydraulic conductivity value in a problem statement. Building permeameters engaged students. They closely examined rock samples, associating texture and appearance with measured hydraulic conductivity values.

Student feedback was used to modify the steps in the methods section of this article (to its present form). They found that seeing a completed device helped considerably. Therefore, the author recommends that instructors build a creased-plastic permeameter, and let students use it as a model. Verbalizing the 10 construction steps ahead of time was also helpful to students.

Food coloring was helpful for visualizing flow through rock samples. It was easier to see than clear water. Many students were surprised how slowly the rocks transmitted water. The experiment worked best in groups of two. This format allowed students to exchange ideas and expedited permeameter construction. For example, one student could prepare plastic sheets while the other trimmed a rock specimen.

\section{Attributes of Creased-Plastic Permeameters -} Creased-plastic permeameters have several attributes that make them useful for a hydrogeology class. Transparent plastic allows students to visualize flow, by injecting dye such as food coloring into the permeameter tube. Dye emerges at the top of the sample, giving students a visual impression of its ability to conduct water. Flow rates can also be calculated, by measuring discharge through the permeameter outlet and dividing by the area of the outlet. Discharge decreases over time as the water level drops in the tube.

All of the supplies needed to construct a creased-plastic permeameter can be obtained from local office supply or hardware stores. The permeameter is easy to build, simple to use, and very inexpensive. A complete permeameter costs less than $\$ 2$. This cost includes the tubing, transparency sheet, electrical adapter, and silicone (fraction of a tube). Rock cutting equipment is more expensive, but readily available in many geoscience departments. Moreover, the cutting equipment can be used to build several permeameters. For departments not having rock saws, a carbide hacksaw blade costs about $\$ 3$, and a masonry rotary blade costs between $\$ 2$ and $\$ 20$. Alternatively, a coring device could be used to extract the rock sample. For a cylindrical sample, the creasing procedure in Steps 2 and 3 could be skipped.

Creased-plastic permeameters can also accommodate repeated tests on a single rock sample. However, numerous tests on a single sample may eventually produce mineral deposits that clog pores and reduce hydraulic conductivity, or induce leakage along the edges of a specimen. Precipitation of mineral deposits is especially likely if local tap water contains a high concentration of total dissolved solids.

Several permeameters can be built at the same time, in an assembly line fashion, to measure more than one sample. Furthermore, several tests can be run at the same time by attaching separate tubes to a single meter stick. The permeameter does not impose tight constraints on the shape of a rock. It accommodates polygons with flat sides. Plastic sheets could also be wrapped around cylindrical samples.

Precautions and Potential Modifications - While the construction procedure outlined above can be modified to accommodate a particular application, certain steps are necessary to attain good results. Silicone was the most effective sealant tested in the study. Other sealants such as latex caulking developed leaks, which lead to erroneously high estimates of hydraulic conductivity. Any alternative sealant should be rated for aquariums or marine applications. Moreover, the sealant should be given at least 24 hours to dry before running water through the permeameter.

Blowouts are most likely at the base of the permeameter. The tabs provide extra contact area for sealing the permeameter to the base sheet. Not using tabs, or folding them outward instead of inward, practically ensures leakage. Contacts between the rock sample and permeameter are also subject to leaking. Cutting a sample into flat or smooth edges facilitates sealing where it contacts the permeameter.

A 0.5 -in $(1.3-\mathrm{cm})$ falling head tube worked well in this study. Air bubbles and capillary effects are potential problems with smaller-diameter tubes. The tube should always be filled slowly to avoid air entrapment. Transparent tape or plastic cable ties work well for securing the tube to the meter stick, because they do not substantially obscure markings on the stick.

Common mistakes made when building creasedplastic permeameters included folding tabs outward instead of inward at the base of the structure, not creating continuous beads of silicone (between plastic parts, or between the plastic and rock), and not allowing adequate drying time between steps. When conducting a hydraulic conductivity test, filling the tube too quickly entrapped air, rendering a false result.

The simplest application of the creased-plastic permeameter is to solid rocks, where it operates in a falling-head mode. It could be retrofitted for a constant-head test (on material such as loose sand having a high hydraulic conductivity) by placing screens inside the chamber, above and below the sample. A constant-head test would also require that a reservoir be attached to the top of the permeameter tube, and that the water level in the reservoir be maintained at a fixed level. Moreover, the hydraulic gradient would need to be less than approximately 0.5 to maintain laminar flow. In a retrofitted, constant-head permeameter, hydraulic conductivity could be estimated by rearranging variables in Darcy's equation, 


$$
K=\frac{Q}{i A_{s}}
$$

where $Q$ is the discharge measured at the outlet and $i$ is the hydraulic gradient (difference between water levels at the reservoir outlet and permeameter outlet divided by the length of the sample). Other variables retain earlier definitions.

Limitations of Creased-Plastic Permeameters - There are also limitations to creased-plastic permeameters that make them more appropriate for education than research. A separate creased-plastic permeameter must be built for each rock to be tested. Therefore, hydraulic conductivity measurements with creased-plastic permeameters take longer than conventional devices.

Furthermore, creased-plastic permeameters cannot withstand air vacuums (which are sometimes used when saturating a sample with water) and may develop small leaks that could give false results. No leakage was encountered when the device was constructed per steps 1 to 10 above, with initial water levels up to $50 \mathrm{~cm}$ above the outlet. Significantly higher water levels in the falling-head tube may induce leakage.

Leaks are more likely for nearly impervious rock samples such as chalk or shale, where larger pressures develop in the bottom of the sample chamber. Tying wire around the outside of a creased-plastic permeameter where it contacts the rock may prevent leaks. However rocks having extremely low hydraulic conductivity values generally require gas devices operating under higher pressures.

Finally, results from any permeameter test should not be extrapolated to represent field conditions. Permeameters give a matrix value, whereas field values obtained from aquifer tests represent a much larger volume. Field estimates of hydraulic conductivity are often larger than laboratory estimates due to secondary porosity from bedding, fractures, and solution cavities.

\section{REFERENCES}

ASTM (American Society for Testing and Materials), 1997, Annual book of ASTM standards, Section 4: Philadelphia, PA, American Society for Testing and Materials.

Gates, A. E., Langford, R. P., Hodgson, R. M., and Driscoll III, J. J., 1996, Ground-water simulation apparatus for introductory and advanced courses in environmental geology: Journal of Geoscience Education, v. 44, p. 559-564.

Hall-Wallace, M. K., 1999, Integrating computers across a geoscience curriculum through an applications course: Journal of Geoscience Education, v. 47, p. 119-123.

Hudak, P. F., 1998, Visualizing groundwater flow fields and contaminant plumes in an undergraduate hydrogeology course: Journal of Geoscience Education, v. 46, p. 132-136.

Lee, M., 1998, Hands-on laboratory exercises for an undergraduate hydrogeology course: Journal of Geoscience Education, v. 46, p. 433-438.

Reichard, J. S., 1999, Switching from a traditional to a computer-based format for introductory geoscience lectures: Journal of Geoscience Education, v. 47, p. 325-330.

Renshaw, C. E., Taylor, H. A., and Reynolds, C. H., 1998, Impact of computer-assisted instruction in hydrogeology on critical-thinking skills: Journal of Geoscience Education, v. 46, p. 274-279.

Schlische, R. W., 1998, Integrating computers into the field geology curriculum: Journal of Geoscience Education, v. 46, p. 30-40.

Todd, D. K., 1959, Ground water hydrology: New York, John Wiley and Sons.

\section{About the Author}

Paul F. Hudak is an Associate Professor in the Department of Geography and Environmental Science Program at the University of North Texas. He received a B.S. in Geology from Allegheny College, M.S. in Geology from Wright State University, and Ph.D. in Geography from the University of California, Santa Barbara. His research interests include groundwater monitoring, aquifer remediation, and geologic hazards.

At the heart of all this calculation lies the deeply held conviction that natural phenomena are, in essence, the consequence of just a small number of physical laws.

\author{
Ivars Peterson "Newton's Clock"
}

